\title{
Nitrate Poisoning due to Ingestion of Cabbages (Brassica oleracea var. capitata L.) (Brassicaceae) in Kitui County, Kenya
}

\author{
Joseph Mwanzia Nguta $\mathbb{i}$ \\ Department of Public Health, Pharmacology and Toxicology, Faculty of Veterinary Medicine, University of Nairobi, \\ Nairobi, Kenya \\ Correspondence should be addressed to Joseph Mwanzia Nguta; jmnguta@gmail.com
}

Received 2 May 2019; Revised 6 August 2019; Accepted 4 September 2019; Published 9 October 2019

Academic Editor: Adriano Sfriso

Copyright (c) 2019 Joseph Mwanzia Nguta. This is an open access article distributed under the Creative Commons Attribution License, which permits unrestricted use, distribution, and reproduction in any medium, provided the original work is properly cited.

\begin{abstract}
Nitrate toxicosis associated with consumption of cabbages (Brassica oleracea var. capitata L.) (Brassicaceae) was diagnosed in a small herd comprising of ten goats in Matinyani ward, Kitui West sub-County of Kitui County in Kenya. The clinical signs were ataxia, ruminal tympany, bluish-brown mucous membranes, rapid and difficult breathing, incoordination, head pressing, aggressive movements, jugular distension, increased heart rates, tremors, and coma. Six goats died of intoxication. Dark brown/ chocolate-colored and poorly clotted blood was the prominent necropsy finding. There was limited froth in the trachea and bronchi consistent with mild pulmonary oedema. There were liver congestion, pericarditis, and enlarged and congested kidneys with pinpoint haemorrhages. Four other affected goats were treated with intramuscular antihistamines and oral administration of ivermectin. No further mortality was observed after the treatment. Cabbages fed to goats had 6.6\% nitrate on dry matter (DM) basis, while ruminal contents had 5.55\% nitrate on dry matter basis (DM). Dark brown blood collected at postmortem had a methemoglobin fraction of $78 \%$. Forage nitrate levels of $0.5 \%$ and above are potentially dangerous, with acute poisoning likely to occur if the nitrate level exceeds $1 \%$. Death can occur when blood methemoglobin levels rise up to 67-90\%. Findings from the current study are indicative of nitrate-nitrite toxidrome associated with ingestion of cabbages.
\end{abstract}

\section{Introduction}

Livestock poisoning from nitrate exposure can be a major cause of morbidities and mortalities in farming systems $[1,2]$. The median lethal dose $\left(\mathrm{LD}_{50}\right)$ of nitrate in cattle appears to be approximately $0.5 \mathrm{~g} / \mathrm{kg}$ of body weight when fed as a part of the animal feed. However, the $\mathrm{LD}_{50}$ of nitrate was found to be much lower following oral administration as a drench, suggesting that the route of exposure and nitrate formulation play a key role in mediation of nitrate toxicity [3]. Acute nitrate intoxication has also been shown to be a function of dietary composition since livestock diets rich in carbohydrates have been associated with decreased nitrate poisoning [4]. Forage nitrate levels of $0.5 \%$ and above are potentially dangerous, with acute poisoning likely to occur if the nitrate level exceeds 1\% [5]. Scientists have considered pastures with nitrate in the range of $0.34 \%$ to $0.45 \%$ nitratenitrogen (1.5-2.0\% nitrate) as potentially toxic [6], while other investigators [7] reported that cattle fed with a poor or a diet deficient in carbohydrates died from a nitrate level of $0.7 \%$ [7]. Nitrate levels of $1 \%$ in forages on dry matter (DM) basis may be expected to result in acute toxicity and death in livestock [8]. When consumed more rapidly than they can be converted in the rumen to protein, nitrates enter the bloodstream as nitrite, which combines with hemoglobin in red blood cells to produce methemoglobin, a form incapable of transporting oxygen. Death occurs as a result of asphyxiation as methemoglobin levels approach $80 \%$ [9].

Ruminants exhibit the highest vulnerability to nitrate poisoning due to the nitrate reducing potential of rumen microorganisms to potentially toxic nitrites. Nitrates $\left(\mathrm{NO}_{3}{ }^{-}\right)$and nitrites $\left(\mathrm{NO}_{2}^{-}\right)$are naturally occurring ions; both are products of oxidation of nitrogen $(\mathrm{N})$ by microorganisms in plants, soil, or water and, to a lesser extent, by lightening. Nitrate is the more stable form of oxidized $\mathrm{N}$ but can be reduced by microbial action to nitrite [10]. The 
reduction of nitrate $\left(\mathrm{NO}_{3}^{-}\right)$to more toxic nitrite $\left(\mathrm{NO}_{2}{ }^{-}\right)$is an intermediate step in the bacterial biochemical sequence of the formation of fully reduced ammonia $\left(\mathrm{NH}_{3}\right)$ which is used to form microbial proteins. Toxicosis by ammonia does not occur in ruminants exposed to nitrate-containing feeds $[11,12]$ since the amount of ammonia produced is limited. In case of rapid ingestion of forages containing high nitrate levels, nitrite will accumulate in the rumen. Nitrite ions are subsequently absorbed through the rumen epithelium into the blood, where they passively enter into the erythrocytes in exchange for chloride ions. The nitrite ion in the red blood cells oxidizes hemoglobin to form methemoglobin which is incapable of transporting oxygen to body tissues, resulting in hypoxia. Signs of anoxia are usually observed when $30-40 \%$ of hemoglobin is converted to methemoglobin, with mortalities occurring when methemoglobinaemia is characterized by more than $80 \%$ of methemoglobin $[13,14]$. Abortion in ruminants due to the fetal hypoxia is a sequel of nitrate intoxication and usually occurs three to seven days after exposure of pregnant dams to toxic nitrate levels $[13,14]$.

The most common source of nitrate toxidrome comprises plants containing accumulated toxic nitrate levels. A number of plants contain levels of nitrates that may be converted in the rumen to nitrites sufficient to cause intoxication. These plants include cabbages, turnips, sugar beets, lettuce, potatoes, and carrots which tend to concentrate nitrate ions, especially if they are grown using a high application of $\mathrm{N}$ fertilizers or grown in well-fertilized soils with manure or if grown during drought. In addition to nitrate toxicosis, induction of goiter has been associated with consumption of large quantities of uncooked cabbages [15]. Crops such as corn (Zea mays L. (Poaceae)), small grains, especially pearl millet (Pennisetum glaucum (L.) R. Br. (Poaceae)), sudan grass (Sorghum bicolor subsp. drummondii (Nees) de Wet (Poaceae)), and sorghum (Sorghum bicolor (L.) Moench (Poaceae)) can accumulate toxic nitrate levels [5]. Weeds such as redroot pigweed (Amaranthus retroflexus L. (Amaranthaceae)), lambsquarters (Chenopodium album L. (Amaranthaceae)), jimson weed (Datura stramonium L. (Solanaceae)), variegated thistle (Silybum marianum (L.) Gaertn. (Asteraceae)), sunflower (Helianthus annuus L. (Asteraceae)), and bindweed (Convolvulus arvensis L. (Convolvulaceae)) can also accumulate large quantities of nitrates under adverse weather conditions $[5,16]$. The greatest potential for toxic levels of nitrates exists in unripe plants and plant parts that are regrown after harvest, such as green potatoes. Factors related to plants and animals have important roles in the development of toxicosis and its outcome [13, 17]. For instance, herbicide application, especially phenoxy derivatives of fatty acids, can enhance nitrate accumulation in plants. The concentration of nitrates in cabbages can vary considerably and may be as much as $1.2 \mathrm{~g} / \mathrm{kg}$ fresh weight and these levels have the potential to cause toxic effects in ruminants [18]. Nitrites induce poisoning due to fatal anoxia when methemoglobin, with a much lower capacity to carry oxygen, is formed [19]. A suspected case of nitrate poisoning in a herd of ten goats fed on cabbages is reported.
The case was reported by the client to the local veterinary personnel approximately thirty minutes after feeding goats with approximately twenty five kilograms (25 kgs) of cabbage leaves collected from Kalundu, a nearby market in Kitui West sub-County of Kitui County in Kenya.

\section{Materials and Methods}

The presented patients were adult Maasai goats comprising eight females and two males and are localized in Kitui central sub-County, Kitui County. The goats were reported to browse on their own in the field. The animal attendant indicated that all the goats were regularly dewormed with $10 \%$ albendazole and were treated monthly against external parasites with Bayticol. The goats had no history of disease and were in good body condition prior to exposure to the cabbages which they had not been previously fed on. In mid-April 2019, a small herd of ten adult Maasai goats in Matinyani ward, Kitui west sub-County, Kitui County, were fed with cabbages that had been collected from Kalundu, a nearby shopping centre in Matinyani ward, Kitui west sub-County, Kitui County in Kenya. Urea and potassium nitrate soil fertilizers are reported to be regularly used to grow cabbages in the fields in Kalundu area. About two hours after cabbage consumption, all the ten goats showed clinical signs of poisoning including ruminal tympany, foam in the mouth, weakness, unsteady gait and incoordination, head pressing, aggressive movements, and biting on objects. Six goats (60\%) which exhibited dyspnea, tremors, ataxia, rapid heartbeat, and terminal convulsions died following a short course of disease. Four goats (40\%) which presented mild toxicosis showed jugular distention, ruminal tympany, hypermetria, incoordination, tachycardia, dyspnea, and sunken eyes. Their mucous membranes were pale to purple.

Presumptive diagnosis of nitrate poisoning was made on the basis of acute nature, clinical signs, and history of cabbage ingestion. Dark brown/chocolate-colored venous blood samples were obtained from the affected goats. The diphenylamine blue test confirmed the presence of nitrates in cabbages, whole blood, ruminal contents, the liver, and the kidney. Urine samples were positive for nitrites when tested by a urine test strip (Combi-Screen, Germany). COoximetry performed on a radiometer $625 \mathrm{ABL}$ showed a methemoglobin (MetHb) fraction of $78 \%$. Two samples of cabbage leaves were taken to the Department of Public Health, Pharmacology and Toxicology (PHPT), a toxicology laboratory for analysis of nitrate content. Methylene blue, the antidote of nitrate poisoning, was not available then, and four affected goats were treated with intramuscular injection of antihistamines as well as oral administration of ivermectin. Fifty milliliters of $10 \%$ oxy-tetracycline was also administered intraruminally. There was no further mortality after treatment. Analysis of cabbage and ruminal content samples by radiopotentiometry revealed $6.6 \%$ and $5.55 \%$ nitrate in dry matter (DM) basis, respectively, confirming the diagnosis of nitrate poisoning in the affected goats. One day after poisoning, all the four treated goats had completely recovered. 


\section{Discussion}

Nitrate intoxication has been reported to mainly occur in cattle found in Western countries [20]. However, in spite of abundance of nitrate accumulator plants [21], data on nitrate poisoning in Kenyan livestock are scarce. Nitrate is found in majority of plants in varying concentrations, but can accumulate to toxic levels under certain conditions, such as drought, cloudy weather conditions, and at night [20]. Nitrate can also accumulate in forages following excessive application of nitrogen-containing fertilizers.

In the present report, repeated use of nitrogen fertilizers and drought could have resulted in high levels of nitrate in cabbages which were fed to the goats. Nitrate levels higher than $15,000 \mathrm{ppm}$ in dry matter (DM) in forages are toxic to goats, sheep, and cattle $[13,17]$. The forage nitrate levels of $0.5 \%$ and above are potentially dangerous, with acute poisoning likely to occur if the nitrate level exceeds $1 \%$ [5]. Outbreaks of nitrate poisoning are usually recorded following exposure of goats to forage containing 3-7\% in DM of potassium nitrate [12]. This observation is in agreement with the findings from the current report, where six goats died following exposure to cabbages containing $6.6 \%$ of nitrate on dry matter basis. Nitrate accumulates in the vegetative tissue, particularly in stalks and low amount in the leaves. Seeds do not generally contain toxic nitrate levels. Heavy fertilization of pastures, herbicide treatment, drought, cloudy weather, and decreased temperature may increase the nitrate concentrations in plants [5]. This observation is in part supported by findings from the current report, where nitrate-containing fertilizers, herbicides, and pesticides had been used. Nitrate toxicity in ruminants is influenced by a number of factors including species, the amount of carbohydrate in the diet, adaptation to nitrate in the diet, and the rate of nitrate consumption. In the current case report, the intoxicated goats did not have prior exposure to cabbages rich in nitrates. In addition, the goats were exposed to large quantities of cabbages containing toxic nitrate levels that could have played a central role in the observed poisoning. The most important factor underlying nitrate toxicity appears to be the rate of ingestion of the nitrate-containing forages. In the current report, the poisoned goats had not eaten any other forage prior to exposure to cabbages containing high nitrate concentrations. Cattle on high energy ration can also tolerate more nitrates [13,17], and this could be the plausible explanation for the increased susceptibility of goats in the current report since the intoxicated goats had no access to an energy-rich ration.

Cabbages are among the different species of nitrateaccumulating plants. It is a common vegetable readily grown along the river banks by all Kenyan communities. Cabbage is an important vegetable known to mankind for over 4,000 years. It is a member of the mustard or cruciferous family (Brassicaceae), which includes mustard, rape, turnip, wasabi (Eutrema wasabi), radish, watercress, many oriental vegetables, and a very important model plant Arabidopsis thaliana.

Healthy animals have normal methemoglobin levels that are relatively constant at $2-3 \%$ of total hemoglobin [22].
When high nitrate feeds are consumed, moderate nitrate poisoning symptoms appear and $20-40 \%$ of the hemoglobin is converted to methemoglobin [23, 24]. Clinical signs reported in the current study are consistent with nitrate-nitrite poisoning. These signs reflect tissue oxygen deprivation and have been reported to become apparent when $30-40 \%$ of hemoglobin is converted to methemoglobin, which is incapable of oxygen transport $[13,14]$, with death occurring as a result of asphyxiation as methemoglobin levels rise up to 67-90 percent [9]. This observation is in agreement with results from the current report where methemoglobin (MetHb) fraction of $78 \%$ was recorded in dark brown venous blood collected from the goats at postmortem. Nitrate poisoning is primarily a problem in ruminants because of the reduction of nitrate to nitrite by ruminal microorganisms. The nitrite ion produces methemoglobin, which cannot react with oxygen, so anoxia occurs [8]. Methemoglobin leads to dark brown or chocolate-colored blood, a common feature of nitrate/nitrite poisoning. Clinical signs of acute nitrate poisoning include diarrhea, salivation, dyspnea, tremors, ataxia, rapid heartbeat, and terminal convulsions. Death may occur within 6-24 hours [8]. These observations are in agreement with current findings where affected goats exhibited difficulties in breathing and had dark brown blood with death being reported within six to twentyfour hours after exposure.

Clinical signs such as head pressing, aggressive behavior, and hypermetria which develop consequent to the central nervous system (CNS) dysfunction and reported in the present clinical case may also be related to severe CNS deprivation of oxygen and resultant hypoxia. Diagnosis of nitrate intoxication is based on observed clinical signs, chocolate/dark brown blood, and exposure to the toxic plant. Diagnosis of nitrate toxicosis can also be confirmed by analysis of the suspected forage or body fluids including urine and serum in live animals and the cerebrospinal fluid or aqueous humour in dead animals [13, 14]. Cabbages fed to goats had $6.6 \%$ nitrate on dry matter (DM) basis, while ruminal contents had $5.55 \%$ nitrate on dry matter (DM) basis . Dark brown blood collected at postmortem had a methemoglobin fraction of $78 \%$. The forage nitrate levels of $0.5 \%$ and above are potentially dangerous, with acute poisoning likely to occur if the nitrate level exceeds $1 \%$. Death can occur when blood methemoglobin levels rise up to 67-90 percent [5]. These findings are in agreement with observations from the current report where $60 \%$ of the affected goats died following consumption of cabbages with $6.6 \%$ nitrate. Methylene blue is the antidote of choice in ruminants with suspected nitrate poisoning. Ascorbic acid is an alternative antidote, but it has a slow onset of action. Intravenous administration of anticholinergic agents such as antihistamines reverses cholinergic effects associated with nitrate intoxication, while intravenous injection of vasoconstrictor agents such as epinephrine is helpful in reversing hypotension, even in cases that are at the point of death [13]. Intraruminal administration of antibiotics also suppresses the reduction of nitrate to nitrite.

As a conclusion, in case of acute mortality in goats fed with cabbages, nitrate poisoning should be considered, 
especially if the cabbages are grown under adverse weather conditions in well-manured farms or when nitrogen fertilizers have been applied. To support any suspicion and to facilitate follow-up, nitrate levels in the forage should be analyzed. In addition, the diphenylamine blue test and nitrate dipstick tests are highly recommended. If possible, serum from surviving cases should be considered. After methylene blue and antibiotic administration immediately following observation of clinical signs, majority of affected goats will recover. However, goat owners should take precaution while feeding their goats on cabbages to minimize cases of nitrate poisoning.

\section{Data Availability}

The qualitative and quantitative data used to support the findings of this study are included within the article.

\section{Conflicts of Interest}

There are no conflicts of interest or financial disclosures relevant to this manuscript.

\section{Acknowledgments}

Special thanks are due to the goats' owner for her kindness and her input in this project.

\section{Supplementary Materials}

The images show gross pathology following postmortem examination. (Supplementary Materials)

\section{References}

[1] M. J. Carrigan and I. A. Gardner, "Nitrate poisoning in cattle fed sudax (sorghum sp. hybrid) hay," Australian Veterinary Journal, vol. 59, no. 5, pp. 155-157, 1982.

[2] C. M. Hibbs, E. L. Stencel, and R. M. Hill, "Nitrate toxicosis in cattle," Veterinary and Human Toxicology, vol. 20, pp. 1-2, 1978.

[3] R. F. Crawford, W. K. Kennedy, and K. L. Davison, "Factors in-fluencing the toxicity of forages that contain nitrate when fed to cattle," The Cornell Veterinarian, Cornell University of Veterinary Medicine, vol. 56, no. 1, pp. 1-17, 1966.

[4] G. E. Burrows, G. W. Horn, R. W. McNew, L. I. Croy, R. D. Keeton, and J. Kyle, "The pro-phylactic effect of corn supplementation on experimental nitrate intoxication in cattle," Journal of Animal Science, vol. 64, no. 6, pp. 16821689, 1987.

[5] B. Puschner, "Anti-nutritional factors in alfalfa hay," in Proceedings of the National Alfalfa Symposium, Las Vegas, NV, USA, December 2000.

[6] M. J. Wright and K. L. Davison, "Nitrate accumulation in crops and nitrate poisoning in animals," Advances in Agronomy, vol. 16, pp. 197-247, 1964.

[7] A. A. Case, "Some aspects of nitrate intoxication in livestock," Journal of the American Veterinary Medical Association, vol. 130, no. 8, pp. 323-329, 1957.

[8] G. Osweiler, T. Carson, W. Buck, and G. Van Gelder, Clinical and Diagnostic Veterinary Toxicology, Kendall/Hunt Publishing Co., Dubuque, IA, USA, 3rd edition, 1985.
[9] A. Michelle, G. Cynthia, L. Jeff, and S. S. Ray, Nitrate Poisoning, Agriculture and Natural Resources Publications, Lexington, KY, USA, 2014.

[10] C. G. Beatson, "Methaemoglobinaemia-nitrates in drinking water," Environmental Health, vol. 86, pp. 31-33, 1978.

[11] S. Casteel, "Reproductive toxicology," in Current Therapy in Large Animal Theriogenology, R. S. Youngquist, Ed., pp. 392-398, W. B. Saunders Co., Philadelphia, PA, USA, 1st edition, 1997.

[12] V. Valli, "The hematopoietic system," in Pathology of domestic animals, K. V. F. Jubb, P. C. Kennedy, and N. Palmer, Eds., vol. 3pp. 101-264, Academic Press, London, UK, 4th edition, 1998.

[13] L. El Bahri, A. Blouin, and J. Belguith, "Toxicology of nitrates and nitrites in livestock," Compendium on Veterinary Continuing Education, vol. 19, no. 5, pp. 643-649, 1997.

[14] S. Casteel and T. Evans, "Nitrate," in Clinical Veterinary Toxicology, K. H. Plumlee, Ed., pp. 127-130, Mosby, Maryland Heights, MO, USA, 2nd edition, 2004.

[15] L. C. Dolan, R. A. Matulka, and G. A. Burdock, "Naturally occurring food toxins," Toxins, vol. 2, no. 9, pp. 2289-2332, 2010.

[16] C. L. Bedwell, D. W. Hamar, M. L. Hoesterey, J. P. Sonderman, and K. G. Odde, "Comparison of four methods for forage nitrate analysis," Journal of Veterinary Diagnostic Investigation, vol. 7, no. 4, pp. 527-530, 1995.

[17] O. Radostits, C. Gay, D. Blood, and K. Hinchcliff, Veterinary Medicine, W. B. Saunders Co., London, UK, 9th edition, 2000.

[18] D. B. J. Bosnir, M. Bevardi, A. G. Boskovic et al., "Nitrate in leafy green vegetables and estimated intake," African Journal of Complementary and Alternative Medicine, vol. 14, no. 3, pp. 31-41, 2017.

[19] T. Kellerman, J. Coetzer, T. Naudé, and C. Botha, Plant Poisonings and Mycotoxicoses of Livestock in Southern Africa, Oxford University Press, Cape Town, South Africa, 2nd edition, 2005.

[20] J. Haliburton, "Nitrate poisoning associated with the consumption of forages or hay," in Current Veterinary Therapy, Food Animal Practice, J. I. Howard, Ed., pp. 278-279, W. B. Saunders Co., Philadelphia, PA, USA, 4th edition, 1999.

[21] M. Aslani, Poisonous Plants of Iran and Their Effects on Animal, Ferdowsi University Press, Mashhad, Iran, 2004.

[22] S. Amir, M. Mohammad, S. Azizul et al., "Non protein nitrogen compound poisoning in cattle," University Journal of Zoology, Rajshani University, vol. 31, pp. 65-68, 2013.

[23] J. L. Johnson, N. R. Schneiderm, C. L. Kelling, and A. R. Doster, "Nitrate exposure in perinatal beef calves," in Proceedings of the American Association of Veterinary Laboratory Diagnosticians, 30th Annual Meeting, pp. 167-180, Lake City, UT, USA, January 1983.

[24] A. Pfister, "Nitrate intoxication of ruminant livestock," in The Ecology and Economic Impact of Poisonous Plants on Livestock Production, L. F. James, M. H. Ralphs, and Nielson, Eds., pp. 233-260, Westview Press, Boulder, CO, USA, 1988. 

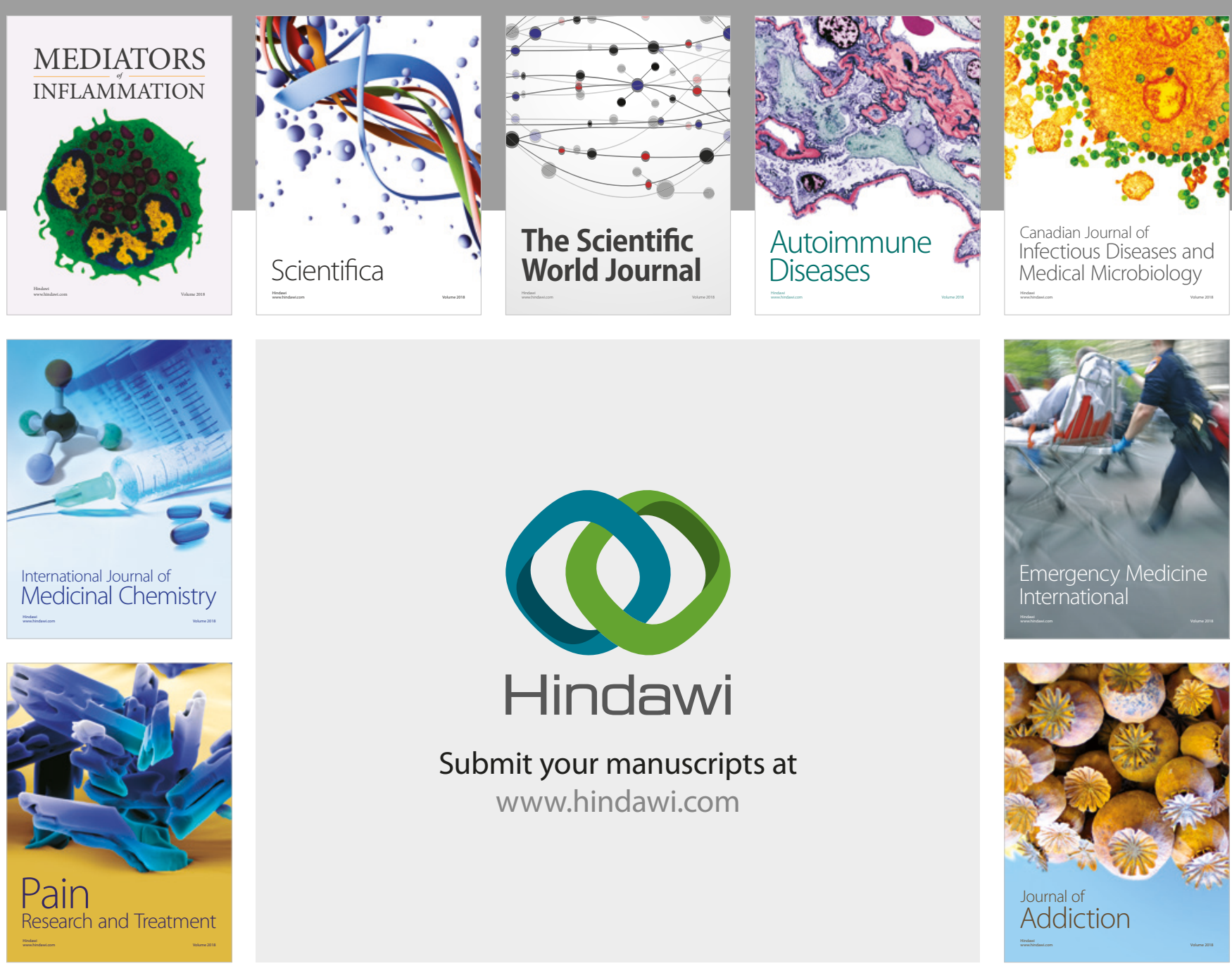

Canadian Journal of
Infectious Diseases and Medical Microbiology

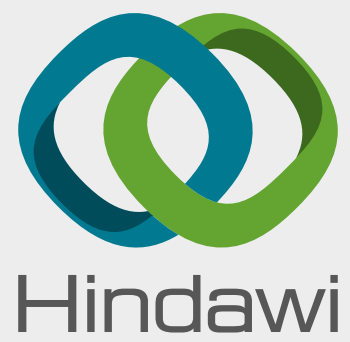

Submit your manuscripts at

www.hindawi.com
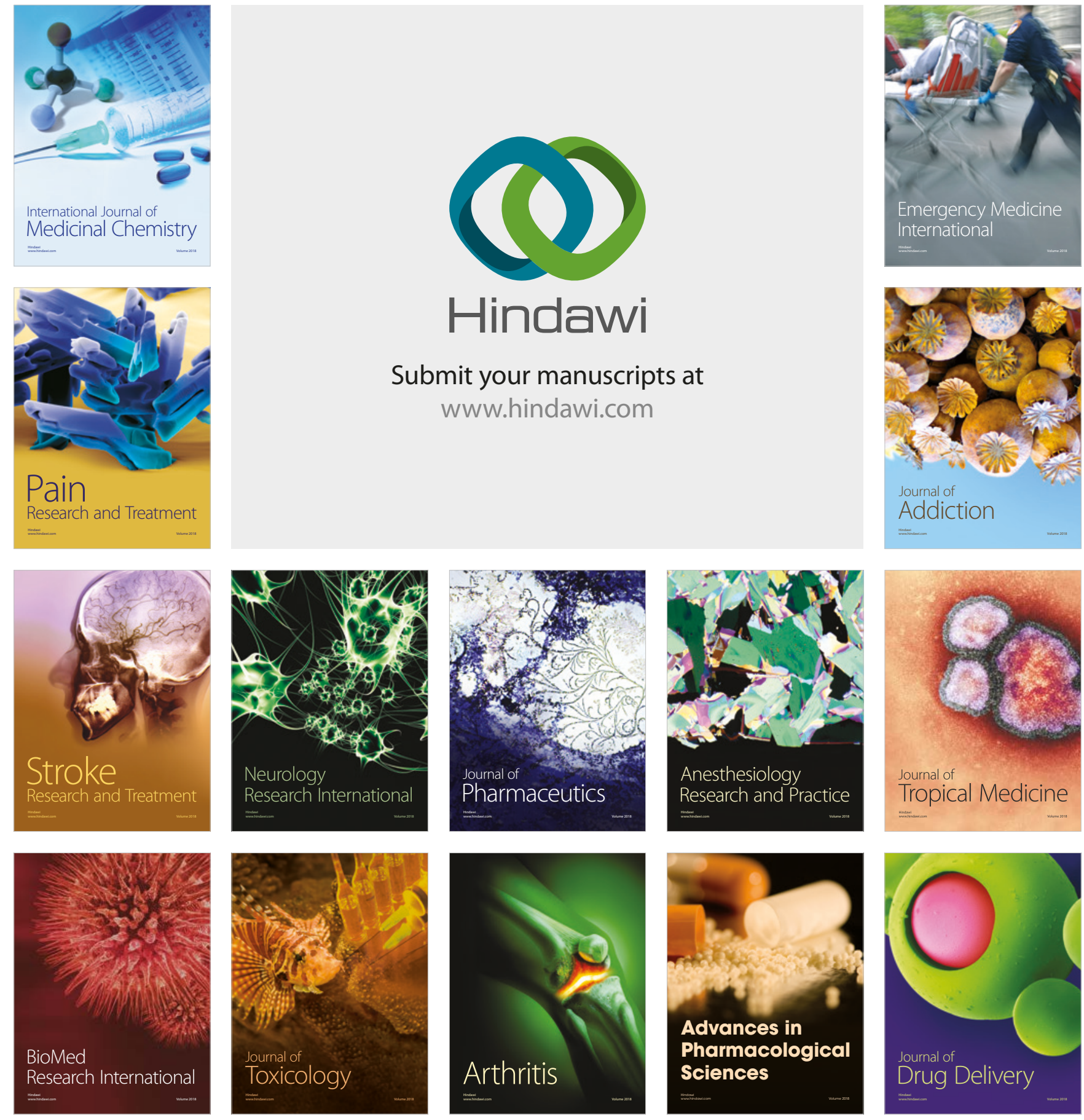